\title{
Family Firms and Negative Social Capital: A Property Rights Theory Approach
}

\author{
Monica Lester \\ Sharad K. Maheshwari \\ P. Michael McLain \\ Hampton University \\ Hampton, VA.
}

Author's Notes

Correspondence concerning the article should be addressed to Monica Lester, 212 Sherman Avenue, Newark, NJ 07114. E-mail: Monica.LesterUSA@gmail.com

\begin{abstract}
Unlike non-family firms, family firms are highly affected by the dynamics of the family. Furthermore, there are differences between minority family firms and non-minority family firms. These differences between the operational performance of non-minority family firms and minority family firms' exist due to the family's tendency to behave collectivistic versus individualistic when extending property rights. Hence, utilizing the property rights theory, this article explains how differences in size, longevity, and financial wealth between non-minority family firms and minority family firms may be better understood by examining the family culture.
\end{abstract}

Keywords: family firms, property rights, negative social capital, minority firms

\section{Introduction}

Recent theoretical opinions have stated that social capital benefited firms by increasing profits (Sherif, Hoffman, \& Thomas, 2006). Profits and access to other funds have a direct effect on firm growth and longevity. For this reason, the discrepancies in these areas (profits, longevity, and growth) between minority family-firms and non-minority family-firms warrant surveying. The moderator of interest relating to these areas of discrepancy is social capital.

Hoffman (2006) suggests that social capital created by common norms reduce transaction costs within the firm. In the context of minority-owned family firms, we believe Hoffman (2006) is overly optimistic. This is by no means an attempt to identify Hoffman as the responsible party for the overly positive presentation of social capital often seen in the literature. This is simply a reference more relevant to the contents of this paper. In fact, the concept of social capital itself emphasizes the constructive features of sociability while neglecting the more harmful features (Portes, 1998).

In reality, social capital is a firm resource that can either be utilized for advancement of the firm or to the competitive disadvantage of the firm. Hence, this paper attempts to present the harmful characteristics of social capital by illustrating that social capital can be negatively assessed. This paper is attempting to bridge the gap in the literature resulting from the tendency of scholars to favor the optimistic view of social capital over the negative. Offering this paper to the literature is an endeavor to 
showcase the concept of negative social capital as being a significant factor in the field of family business.

For the purposes of this paper, the usefulness of social capital to the firm is measured in terms of its delivery of human capital, additional social capital, and other intangible and tangible resources. If social capital does not offer the firm access to additional resources that are relevant, then maintaining the social connection or investing in such a connection becomes a liability to the firm-this is negative social capital. It is reasoned that differences in the amount of negative social capital present in firms account for discrepancies between minority family-firms and non-minority family firms that relate to size, profit, and longevity.

Negative social capital can eat away at the family-firm resources and stunt growth and minimize profits and longevity by compelling family firm-owners to give non-owning family members property rights. The resources that a firm owns are not the physical resources, but instead are the property rights to those resources (Coase, 1960). And if those property rights are misappropriated, the resources attached to those rights are not readily available for the benefit of the firm. Regardless of the size of the firm, if the firm efficiently utilizes its internal and external resources, then the firm can experience efficient growth (Penrose, 2009). And, growth is important to understanding firms' profitability and longevity. Growth, leads to increased size; increased size often leads to increased profitability; and profits may lead to survival. However, this trend is highly dependent on the efficiency and effectiveness of the firms' management (Nwankwo \& Osho, 2010).

\section{Literature Review}

\section{Social Capital}

Social capital was first used by L.J. Hanifan in his 1916 article The Rural School Community Center. Hanifan (1916) was concerned with enhancing the conditions of rural schools and was referring to the great advancements witnessed at a rural school community in West Virginia. Hanifan (1916) attributed the advances to a phenomenon defined as social capital. Social capital, according to Hanifan (1916), is that factor in life that makes tangible substances count most in the daily lives of a people, namely, the social intercourse among a group of individuals and families who make up a social unit. Over the years, this conservative definition of social capital has been improved upon and borrowed by various disciplines. In fact, at one juncture, social capital was one of the most dynamic areas of inquiry in the social sciences (Durlauf, 2002). This progression eventually approached the field of economics and management. For this reason, this paper attempts to expand the use of social capital even further by flipping the coin and looking at the factor that makes tangible substances count least in the lives of people. In other words, what about the negative aspect of social capital?

At present, social capital literature is continuing to move toward an understanding of how social norms and social structures arise and prescribe individual behaviors (Durlauf, 2002). In this particular examination, these norms and structures will be viewed from the perspective of family firms and explained in terms of how they restrict behavior and lead to negative social capital.

The social capital stated in this paper aligns itself with the social capital Putnam (2000) calls connections among individuals which are norms of reciprocity. These norms of reciprocity dictate the rules by which individuals create, terminate, and maintain social ties. One way to measure the usefulness of these social ties (i.e. a form of social capital) as a resource for the firm; is by understanding its delivery of human capital and additional social capital. Human capital is the knowledge, experience, and education that people possess. This capital is the property of the individual and is only leased or rented to the enterprise/firm (Wiig, 2004).

Having social capital that connects one to human capital is like having a means to access a source of information. Raw social capital refers to as structural social capital. This is simply the network connection between individuals (Nahapiet \& Ghoshal, 1998). It is analogous to a highway that connects two people who live in different cities. By having this connection, the individuals can travel along the 
highway and exchange knowledge (human capital) and assist one another in making connections (structural social capital) to other people.

Like any other highway, there are rules of travel; hence, this exchange is more efficient if the rules of traveling along the highway is understood and acknowledged by both parties; so this leads to the introduction of cognitive social capital. Cognitive social is shared interpretations held by individuals at both end of the structural highway (Nahapiet \& Ghoshal 1998). Another way to ensure efficient transportation through social networks is by securing quality relational social capital. Relational social capital is like the quality of the structural social capital (the highway) being used to transport information. All should agree that a highway with no potholes or fallen trees blocking its path will cause for more efficient transportation. For this reason, relational social capital is where the quality of social capital lies.

From the inception of the term social capital, Hanifan (1916) considered the human resources of the people within the community when he spoke of the activity of accumulating social capital.

Continuing this thought, this paper hopes to establish that valuable social capital does not accumulate because one knows people; it accumulates because one knows people who 1) know other people and 2) know things. This dimension of social capital is called relational social capital (Nahapiet \& Ghoshal, 1998). Along with structural and cognitive social capital, relational social capital that exists within the family becomes enmeshed within the social capital of the firm. When it comes to the family firm, the family and the business do not exist as distinct entities but, instead, co-exist as an entangled network (Pearson, Carr, \& Shaw, 2008). For this reason, the relational social capital (the nature and quality of the connections) that family-firm owners choose to maintain (Nahapiet \& Ghoshal, 1998) must be an asset to the firm if it is to positively impact the firm, because it is the family firm's behavioral and social resources that create familiness (Pearson, Carr, \& Shaw, 2008).

\section{Familiness}

Familiness is the idiosyncratic bundle of resources and capabilities that a firm accumulates due to the systemic interactions of the family (Habbershon, Williams, \& MacMillan, 2003) which leads to the advancement of the firm or the demise of the firm. Unlike non-family firms, family firms are highly affected by the dynamics of the family. For this reason, the components of familiness must be collectively pursued by all members of the family who hold property rights to firm resources. These components of familiness are as follows:

a) an intention to maintain family control of the dominant coalition;

b) a unique, inseparable, and synergistic resources and capabilities arising from family involvement and interactions;

c) a vision held by the family for trans-generational value creation; and

d) A pursuance of such a vision (Chrisman, Chua, \& Litz, 2003, pp. 470-471).

As family members interact and work to maintain the operations of the family firm, if they are not aligned with respect to the components of familiness, negative social capital can begin to accumulate. Bubolz (2001) states that family is not only a source of social capital, but it is also a user of social capital. Hence, maintaining social connections with family members who behave in a manner that is detrimental to the family firm's vision, pursuance of that vision, and development of resources and capabilities, is the process for creating negative social capital.

In general, all family members who hold property rights to the resources of the family firm must create more social capital than they use. Company assets are an aggregation of liabilities and property rights. Hence, those owners holding property rights must utilize sources of social capital in order to create a successful environment for the venture and compensate for liability (Sype, 2011). Efficiently managing rights and controlling liabilities positively affect overall company assets. And, efficiency requires adherence to certain rules of engagement.

Again, consider our analogy of the highway. If structural social capital (the highway) only has one party following the rules of travel (cognitive social capital) or if the transportation of is unidirectional, the quality (relational social capital) of the highway deteriorates. Which means the 
structural social capital highway is maintained by a bi-directional, balanced transportation of resources that follows the rules of travel.

\section{Property Rights}

In 1960, Ronald Coase provided one of the first formal treatments of the property rights of the firm. Coase declared that if each firm had property rights to a certain resource and the firms could not coexist, then the firm producing more benefits from the resource in question should be the firm to retain property rights (Coase, 1960). From these beginnings, property rights theory (PRT) has evolved into a more complex theory addressing legal property rights as well as the social institutions in which these rights exist (Libecap, 1989). Because property rights deal with control of firm behaviors, the benefits of these behaviors, and the social interactions that occur as different firms exercise their property rights; we use this theory to explain the relationship between social capital and human capital in family firms. As a result, property rights will be defined as the right to have access to revenues (resources) produced by the family firm (also a resource); the right to utilize those resources; and the right to control who else has access to those resources.

As mentioned above, this paper is particularly preoccupied with property and the rights to use property in family firms. To be more precise, we are concerned with the human capital and social capital made available to the principal decision-maker(s) of the family firm through family ties. At this point it is important to highlight assumptions of previous researchers. Coase (1960) stated that property rights should be reserved for those who could create the most benefit. Almost a half century later, scholars are still expanding PRT according to this assumption. Kim and Mahoney (2010, pp. 810) write, "It is anticipated that property rights will be allocated to those who can generate greater economic value from the utilization of particular property rights." So, this paper poses the question: What if property rights are allocated based on factors other than this concept of generating greater economic value? Contending that this is more often the case in minority-owned family firms versus non-minority family firms, this paper hopes to present the theoretical concept of negative social capital and express that due to negative social capital, minority family firms in general have smaller size, shorter longevity, and fewer profits (Farlie \& Robb, 2007; Masuo \& Malroutu, 2008).

\section{Minority Family Firm and Social Capital Ties}

Too little attention has been paid to the effects that families have on entrepreneurship (Aldrich \& Cliff, 2003). This is unfortunate because family involvement and family intentions can affect the behavior of family business members with regard to capturing opportunities, resource acquisition and deployment, and performance (Chang, Memili, Chrisman, Kellermanns, \& Chua, 2009). By modifying their behavior to adhere to family expectations, principal decision-makers of the family firm can inadvertently work counterproductively.

This counterproductive behavior may more prevalent in minority family firms and leads to the creation of more negative social capital as compared to non-minority family firms. Before disclosing how principal decision-makers of minority family firms engage in behavior that leads to the production of negative social capital, the minority family must be assessed from an overall perspective. Family firms, unlike nonfamily, firms are heavily influenced by the dynamics of the family; hence, recognizing characteristics of the minority family is crucial. For clarification purposes, the minority family of choice is the African American family. Any minority family can exhibit the characteristics expressed below, but the African American family seems to have the strongest expression of these traits.

Consider the structure of an African American family compared to that of a Caucasian family. It is worth noting that extended living has been shown to be more prevalent among African American families than Caucasian families (Puryear, et al., 2008; Ruggles, 1994). Therefore, it is logical to consider that African American family firms on average will have more African American family members outside of the traditional nuclear family unit with extended privileges that influence the family firm. This is not to 
say that African American family firms are less prudent in safeguarding the resources of the family firm. It is a suggestion that factors, such as living arrangements influence the family firm differently.

For example, other differences between African Americans and Caucasians worth noting are the tendency to marry and the prioritizing of family and business. African American family firms tend to have more owners who are not married (Masuo \& Malroutu, 2008), and according to Puryear, et al. (2008), they tend to put family before business. These differences are imperative to understanding differences between minority and non-minority family firms; because these differences play critical roles in who has access to the property rights of the firm's resources.

In addition, the extended living arrangement is an expression of the collectivistic culture that is inherent to African American families. Due to this collectivistic culture, African American families focus more on making decisions that are perceived as beneficial to the group versus those that are beneficial to the individual. As a result, principal decision-maker of minority family firms can be compelled to make decisions in the interest of the family with little regard for the consequences the decisions may have on the firm.

This change in behavior occurs due to the structural (raw) social capital the principal decision maker has with each family member. Social capital is simply a social connection with no value associated (Fulkerson \& Thompson, 2008). When it comes to the firm, this "raw" social capital can be accumulated in many ways - attending conferences, participating in town meetings, becoming affiliated with professional associations, and developing relationships with individuals who have information pertinent to the firm.

After the structural social connection is formed, the relational social capital - the social capital that holds value-- is determined by the human capital and additional social capital that structural social capital makes accessible. For example, which is more valuable or considered "more positive" for a business owner? -A social connection with an unskilled extended family member or a social connection with the local alderman? It must be mentioned that the structural social capital with the unskilled extended family member is a resource that could potentially benefit the firm, but it would be a rare event if this resource outweighed that of affiliation with the alderman. An alderman can give the firm notice on changes in the zoning laws or introduce the firm-owner to other politicians, while an unskilled family member may be able to refer a few customers. This comparison of human capital and additional social capital is important to consider because this is where relational social capital gets its worth.

Like structural social capital, human capital can be accumulated in many ways. Human capital can be defined as knowledge, skills, and abilities (KSA's) that an individual possesses. These KSA's can be attained through education, training, and experience. For this reason, the KSA's of the alderman amounted to more worth to the firm because the sharing of his knowledge can be utilized by the firm to bypass major expenses and realize economic rents. This does not mean the unskilled family member has no quality relational social capital relevant to the firm; however, the value of the KSA's that the unskilled family member presents would at best save the firm a trivial amount of money on advertising by letting a couple of friends know you are open for business.

\section{The Creation of Negative Social Capital}

It is not enough to discuss structural social capital and how it creates access to additional capitals, the normative setting of the firm must also be considered. Within any firm, there is a culture and the culture carries a set of norms dictating how individuals interact. Family firms have expectations of interactions based on their shared goals, beliefs, and norms. It is the norms that provide the rules of interaction with social networks. Without these rules, predetermined goals cannot be accomplished. It is also these rules that complicate the utilization of resources (Reimer, Lyons, Ferguson, \& Palanco, 2008).

Thirty-years ago, the major culprit causing minority firms to have inferior performance was thought to be financial capital. Banks were believed to routinely discriminate against African Americans seeking to secure business loans (Hirsch, 1989). In addition, minorities were discriminated against during the recruiting phase (Lee, 1987) when seeking gainful employment, so start-up capital for minorities was 
greatly restricted (Robb \& Farlie, 2007). However, in cases where minority firms have the same amount of financial capital as non-minority firms and still experience inferior performance, other factors must be explored.

This paper will concentrate on the complication resulting from conforming to norms despite the misuse of social capital, human capital, and other firm resources. Like so many types of minority families, the minority family firm adheres to norms that encourage behavior viewed as "in the interest of the group." A norm of this sort is thought to reinforce social support that builds social capital and strengthens families (Coleman, 1988). However, this is not always the case (Molina-Morales \& Martinez-Fernandez, 2009). Social capital is a connection among individuals with norms of reciprocity (Putnam, 2000). If the norm of reciprocity is gravely imbalanced, there will always be negative social capital present.

Sacrificing one's own desires and goals for the betterment of the group may appear to strengthen family ties; however, when the property rights theory is considered, giving access of firm resources to those who only benefit on an individual level does not make good business sense. Assuming the goal of the entrepreneur is to ensure longevity, constantly increase profits, and to grow the firm, managing property rights responsibly would be first priority. More often than not, this is not the case in family-firms with a collectivistic culture.

The property rights in collectivistic cultures with extended families tend to be defined by kinship structure rather than individually. As a result, the differences in the amount of property rights privileges between the nuclear family and the extended family are not well-defined (Khavul, Bruton, \& Wood, 2009). The absence of well-defined property rights disperses accountability and strains resources making profitability from those resources hard-pressed (de Soto, 2000). Hence, when minority family firm owners allow kinship ties to dictate how property rights of firm resources are exercised, the profitability of those resources diminish. Without profits, a firm cannot grow and over time will begin to decline. And, a dwindling firm eventually dies. Therefore, the observable fact that a larger proportion of minority family firms experience little to no growth, lower profits, and more business failures is anticipated.

Minority business owners tend to pursue entrepreneurship in an effort to self-actualize and to earn a livelihood (Puryear, et al., 2008). Utilizing the skills, self-employed minorities tend to do substantially better in the labor market than those who are salaried (Masuo \& Malroutu, 2008). Self-actualization and earning a livelihood are also goals of non-minority business owners; however, there is a noteworthy difference in motivation. Many minority businesspersons pursue entrepreneurship to escape discrimination in the workplace that marginalizes their abilities (Masuo \& Malroutu, 2008). They do not go into business to actively engage in the art of entrepreneurism. The commitment is to escape discrimination; not to engage in the entrepreneurial process. According to Kirzner (1973) the entrepreneurial process is a steady, conscientious progression toward market equilibrium that is brought about by an alert entrepreneur. The entrepreneur seeks opportunities that minimize transaction costs and maximize profits through ever improving resource allocation (Kirzner, 1973). In other words, the entrepreneur sees the big picture and works to make the firm attuned to the market. Without a focus on the entrepreneurial process, the firm will not emerge superior.

While many scholars have speculated about differences in profits, longevity, and growth between non-minority firms and minority firms, the literature addressing these differences has remained deficient. Theories have explained these differences based on a series of individual business decisions from a mainstream, Euro-American perspective (Masuo \& Malroutu, 2008). This approach has overlooked the group dynamics and the reliance on group resources that are unique to minorities (Masuo \& Malroutu, 2008). Minority family firms have a more collectivist culture than non-minority family firms. For this reason, minority family firms behave differently and employ familiness in ways not easily explained from an individualistic perspective.

Current literature looks at family business in a nuclear family context - it suggest/ignores family arrangements that are unique to minority family firms. Literature describes cousin consortium as being a phenomenon seen in family businesses after the second generation of firm owners (Gersick, Davis, Hampton, \& Lansberg, 1997; Lansberg, 1999). Cousin consortium describes the late life cycle of the firm where ownership becomes diluted because it is divided among several family members (Gersick, Davis, 
Hampton, \& Lansberg, 1997). This is not the case for African American family firms. African American firms tend to reach this cycle at the beginning stage of the firm's development (Smith, 2009). Before the firm can fully sustain itself, there are cousins and other extended family members clamoring to claim property rights to the resources of the family firm. This dilution of property rights weakens profits, minimizes the size of the firm because revenue is not being re-invested in the firm, and diminishes longevity.

The early onset of the cousin consortium cycle is due to the collectivist environment unique African American family firms and this alignment influences the entrepreneurial process and its outcome more than it does in the mainstream culture (Masuo \& Malroutu, 2008). Although current literature is beginning to address how families impact the success of the firm, there is still not enough attention being focused on the differences of family dynamics between minority families and non-minority families (Masuo \& Malroutu, 2008). For example, African American entrepreneurs are more likely to be single than Euro American entrepreneurs (Masuo \& Malroutu, 2008; Reynolds, Carter, Gartner \& Greene, 2004). Marital status has been linked to positive returns in profits. How much marital status affects profits is unclear. Bosma, van Praag, Thurik, \& de Wit (2004) stated that entrepreneurs who had the emotional support of a spouse earned approximately $40 \%$ more than those who did not have such support. Reynolds, Carter, Gartner \& Greene (2004) on the other hand, attributed only small and varied differences to marital status.

This finding is significant because although African American family firms are more likely to have extended family they are least likely to marry. Hence, the extension of property rights may be offered to an extended family member instead of a mate. Other trait worth mentioning is collectivism. Although this paper focuses on the African American family firm, their behavior is similar to the findings of Masuo \& Malroutu (2008). Like the minority groups studied by Masuo \& Malroutu (2008), African Americans tend to hold a collectivist attitude when interacting with extended family members. Due to the fact that African American entrepreneurs tend to fare better than family members who are not selfemployed, they are often sources of financial and non-financial support. This support is provided despite any inefficiency the entrepreneur may have. Instead, support is given in adherence to the governing custom of collectivism and loyalty to the family.

The act of adhering to a norm that negatively impacts the individual and/or the firm is where the formation of negative social capital happens. Negative social capital is the product of the behavior. In this case, the behavior is granting access to the property rights of firm resources to those who do not sufficiently contribute resources to the firm. The pressure to adhere to supporting collectivism outweighs the desire to ensure the success of the firm.

Considering the marital status and the presence of a collectivist culture is the tip of the iceberg when attempting to explain the differences between minority and non-minority family firms in terms of profits, longevity, and growth. The scope of this paper only expands so far; however, with every additional layer, the differences in profits, longevity, and growth observed between the non-minority and the minority family firms become more pronounced. Figure 1 illustrates the distinctiveness of the two types of firms.

Chang, Memili, Chrisman, Kellermanns, \& Chua (2009) found that minority (Hispanics) tend to depend on family members much more than they do external support systems--this is also the case for African Americans. Consequently, the principle decision- maker in minority family firms seldom assesses whether or not an extended family member who is demanding property rights has social capital or human capital that is beneficial to the family firm. Business rational is outweighed by the obligation of the firmowner to offer assistance. In non-minority family firms, family members must prove their worth before receiving assistance from the principal decision-maker (Masuo \& Malroutu, 2008). In contrast, in African American family firms the principal decision-makers bear the burden of showing commitment to the family without any expectations of repayment. 

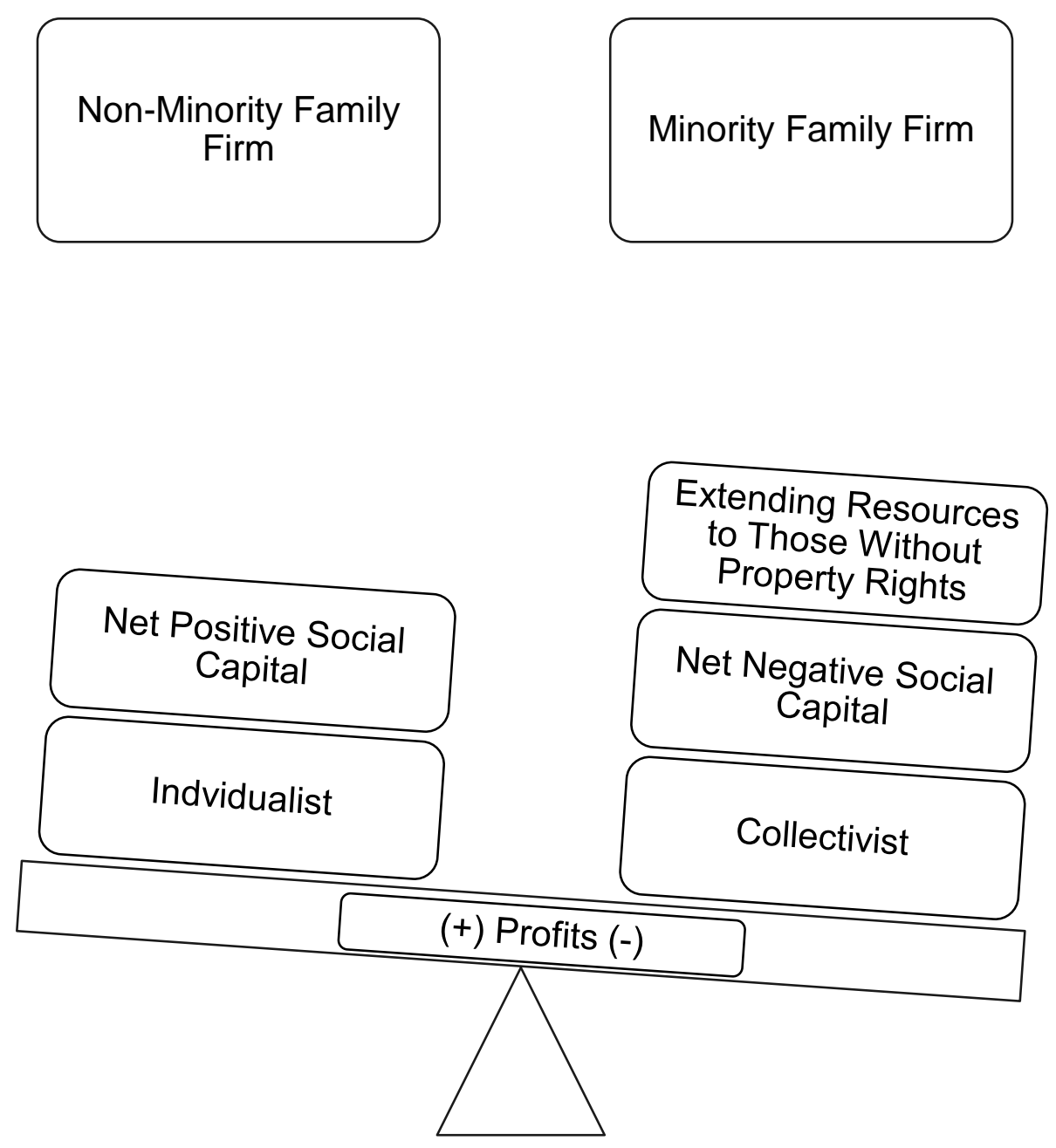

Figure 1. A comparison of the non-minority and the minority family firm. This figure illustrates how collectivism, negative social capital, and diluted property rights negatively impact profits.

Despite having the goal of being fair for the group, it is important to point out that the "norms of reciprocity" regarding relational social capital are not necessarily balanced or fair. Therefore, maintaining structural social capital that has no positive impact on the firm is a self-defeating act that overtime becomes negative social capital. When Hanifan (1916) spoke of the accumulation of social capital, he was referring to positive social capital. If structural social capital influences one to distribute resources (knowledge, access to economic rents, and jobs) in one direction, it converts to negative social capital as shown in Figure 2.

\section{The Creation of Social Capital in the Family Firm}

Collectivism can have a positive impact on the firm if the goals of the firm and the goals of the group are aligned. Hoffman (2006) suggests that [family] social capital created by common norms reduce transaction costs within the firm. In the context of minority-owned family firms, we believe that the majority of literature is overly optimistic. In theory, negative social capital is just as probable as "positive" social capital. When norms through the medium of social capital influences behavior not 
aligned with the firm's goals, the firm loses use of resources misappropriated to the group. The loss of these resources reduces the firm's ability to increase profits; and profits are not on hand to increase growth and increase the life of the firm. This is definitely no "reduction" in transaction costs.

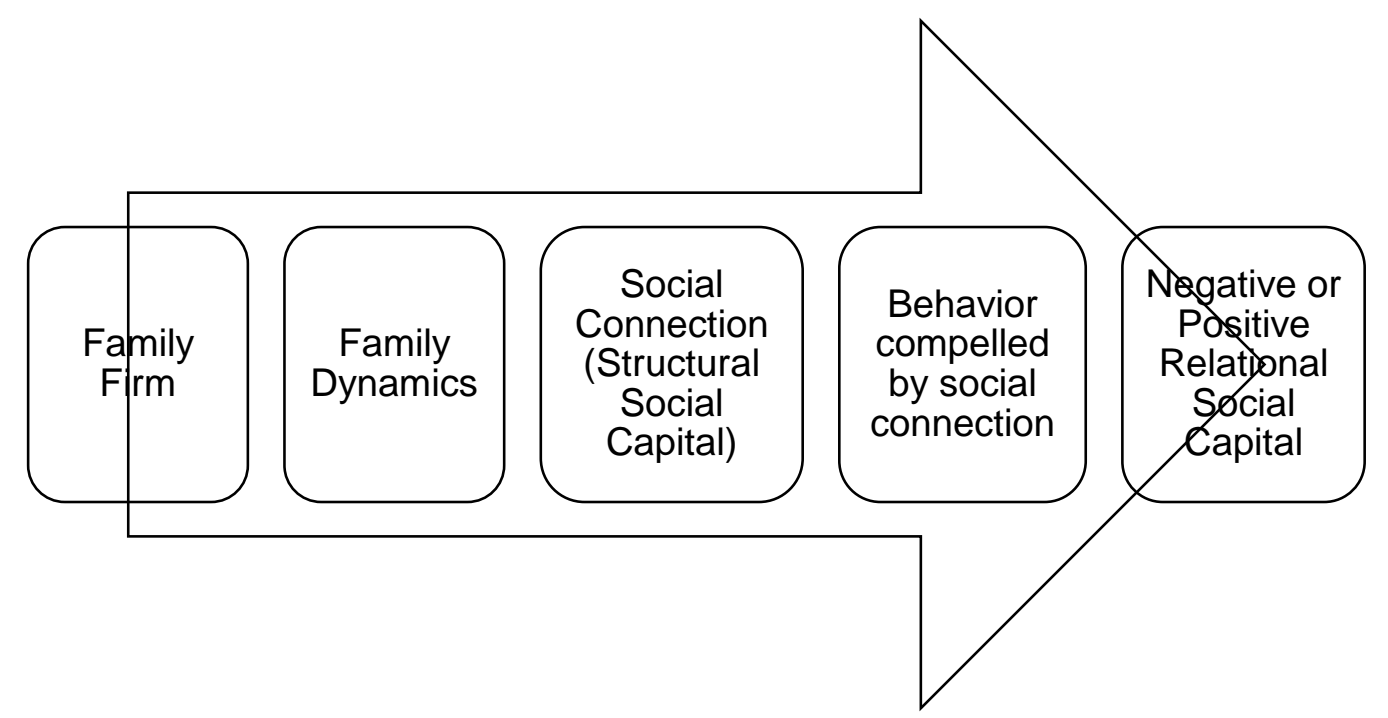

Figure 2. The process of how family dynamics in the family firm generate either positive or negative social capital.

This misalignment of group goals with firm goals can explain reports that minority firms continue to underperform despite equal access to financial capital. For instance, although minorities are more likely to start a business than Euro Americans (Reynolds, Carter, Gartner \& Greene, 2004), they experience the least amount of growth. This phenomenon can be explained by the presence of collectivistic behavior and the misuse of firm resources. Again, this misuse of firm resources by principal decision-makers is due to the presence of social constraints destined to become negative social capital.

Minority business owners tend to have less human capital in the form of managerial experience and education. This tends to negatively impact profits of the firm (Puryear,et al., 2008). These findings coupled with negative social capital account for decreases in growth rate and longevity among minority family firms also. As behaviors by the principal decision-makers in the family firm are modified based on structural social capital, relational social capital can become either positive or negative. This negative social capital can have a domino effect on the family firm - affecting both tangible and intangible resources important to the success of the firm.

Tangible resources that are absorbed by negative social capital can include profits, product, and company property. Intangible resources can include time, energy, and knowledge (human capital) of the principal decision-maker of the firm. Like any other resource, intangible resources of the firm have property rights also. Human capital, for instance, belongs to the individual and the individual leases or rents their knowledge (Wiig, 2004). However, instead of channeling KSA's (knowledge, skills, and abilities) into maintaining and advancing the firm, the principal decision-maker is leasing her knowledge to family members at an economic loss. Again, the greatest economic rent is not being realized.

This access to human capital through the medium of social capital is binary, and of course, entrepreneur has access to the human capital that extended family members have as well. The only issue that arises is the quantity and quality of the human capital going back and forth. The extended family member reaps significantly more than she invests; the firm and the principal decision-maker reap significantly less than invested.

All in all, like other resources of the firm, human capital has an owner who has the right to control who has access to that capital. Human capital is a collection of the individual's experiences, 
skills, knowledge, and abilities; and an imbalance in relational social capital is the idea environment for negative social capital. If one party has significantly more human capital to give than the individual on the other end of the social connection, sooner or later at least one party will experience negative social capital. Under favorable conditions, human capital and social capital merge and create an environment where the firm profits, grows, and has longevity (Carter, Brush, Greene, Gatewood, \& Hart, 2003). The entrepreneur would utilize the responsibility of having the property rights to the firm and its resources pragmatically, and would only allocate property rights to those who could generate the greatest economic value (Kim \& Mahoney, 2010).

These property rights are often negotiated instead of inherited, and as resources are founded and developed within the firm, property rights are determined by the principal decision-maker(s) of the firm. Bargaining power, at a given point, is viewed as a function of a stakeholder's role in rent generation,(Blyer \& Coff, 2003). So, if the stakeholder - principal decision-maker-- does not generate rent (profits) and does not create valuable unions, the process of determining property rights becomes futile. In other words, if negative social capital encourages illogical business practices why go through the process of founding a firm? Is the struggle for nothing?

\section{Future Research}

Twenty-five percent of African Americans live below the poverty line as compared to EuroAmericans (Singh, Knox, \& Crump, 2008). Singh, Knox, \& Crump argue that one way to change this is through African American entrepreneurship. This is motivating and could be the focus of future research. If the content of this paper is considered when seeking out ways to improve the health of minority family firms, the results could benefit the society at large (Guiso, Sapienza, \& Zingales, 2004).

According to an article published by the US Department of Labor Bureau of Labor Statistics, the racial and ethnic make-up of the United States labor force is rapidly diversifying (Toossi, 2002). This means there can be great consequences for the success and/or failure of minority family firms. The longevity, growth, and profits of all family firms are critical to society. Minority family firms are more likely to hire minorities than non-minority family firms (Singh, Knox, \& Crump, 2008); thus, as the population becomes more diverse, the discrepancies between minority and non-minority poverty levels can be mitigated by securing the success of minority family firms.

This being the case, a closer assessment of ethnicity within the family firm is crucial. Understanding ethnic and family context is vital to understanding the entrepreneurial process as a whole. (Danes, Lee, Stafford, \& Heck, 2008) The impact ethnicity has on business decisions as well as customers, employees, suppliers and financiers (Peredo \& Chrisman, 2006) should be explored and may lead to long-term research opportunities. Also, investigating the impact of positive social capital on financial developments within historically disenfranchised communities could prove essential.

\section{Conclusion}

Minority businesses tend to compete based on their value systems (Enz, Dollinger, \& Daily, 1990) and consciously make business decisions that adhere to norms rather than tried business strategies. The value systems offer partitioned components of property rights to members of the family who are not able to create the most economic benefit to the firm. Due to this, the discrepancies between minority family firms and non-minority family firms are explained in terms of the property rights theory.

Property rights are defined as the right to have access to revenues (resources) produced by the family firm (also a resource); the right to utilize those resources; and the right to control who else has access to those resources. Family members are given access to firm revenues for their personal utilization; however, the firm is not realizing significant return on these investments.

The particular type of social capital described in this paper is negative social capital. Negative social capital has been acknowledged, but rarely discussed in any depth. We use this concept to explain the phenomenon of structural social capital being converted into a negative return for the firm and applied 
it to minority family firms. This in-depth review is made necessary because the field of business and sociology alike have been overly optimistic in describing the impact of social capital (Molina-Morales \& Martinez-Fernandez, 2009).

The collectivistic behavior of African American family firms may or may not create positive social capital and have a positive impact on minority family firms. Karra, Tracey, \& Phillips (2006) state that altruistic behavior can create a self-reinforcing system that encourages family members to be thoughtful and can ultimately lead to improved firm performance. In addition, Karra, Tracey, \& Phillips (2006) state that collective ownership generates an organizational culture that encourages risk-taking.

One example of this risk-taking is the tendency to convert structural social capital into negative social capital. The presence of negative social capital causes the firm to experience lower profits, less growth, and shorter longevity. Harris (2009) states that although ethnic group identity can give businesses an early boost, in the long run it can be limiting. The assertions of this paper concur. Steier (2007) concludes that it is in fact weak social ties acquaintances, not the strong social ties from family that offer businesses more returns. Family can act as a conduit to these valuable social connections, but the family themselves are not necessarily the most valuable source of long-term social capital and human capital.

Again, while the family may contribute human capital, social capital, and financial capital during the nascent phase of the family-firm (Dyer, 2006) the ongoing contributions of family members are not always positive. Understanding the formation and delimitation of property rights is another way of exploring economic problems. When people deal with each other, each stands to gain from, and is willing to spend resources in order to capture a larger portion of the available pie. This dealing entails divergence between private and social costs (Barzel \& Kochin, 1992). For minorities the entrepreneurs of the family firm seem to be dealing for a larger portion of family acceptance while family members are dealing for a larger portion of the firm's resources. Every time property rights concerning the family firm are extended to a family member who--by principle of the property rights theory - is not entitled to those rights, the principal decision-maker(s) of the family firm have over paid for the social and human capital belonging to that individual.

\section{References}

Aldrich, H. E., \& Cliff, J. E. (2003). The pervasive effects of family on entrepreneurship: Toward a family embeddedness perspective. Journal of Business Venturing, 18(5), 573596.

Barzel, Y., \& Kochin, L. (1992). Ronald Coase on the nature of social cost as a key to the problem of the firm. Scandinavian Journal of Economics, 94(1), 19-31.

Blyer, M., \& Coff, R. W. (2003). Dynamic capabilities, social capital, and rent appropriation: Ties that split pies. Strategic Management Journal, 24(7), 677-686.

Bosma, N. V., van Praag, M., Thurik, R., \& de Wit, G. (2004). The value of human and social capital investments for the business performance of start-ups. Small Business Economics, 23(3), 227-236.

Bubolz, M. (2001). Family as source, user, and builder of social capital. Journal of Socio-Economics, 30(2), 129-131.

Carter, N., Brush, C., Greene, P., Gatewood, E., \& Hart, M. (2003). Women entrepreneurs who break through to equity financing: The influence of human, social, and financial capital. Venture Capital, 5(1), 1-28.

Coase, R. (1960). The problem of social cost. Journal of Law and Economics, 3, 1-44. Coleman, J. (1988). Social capital in the creation of human capital. The American Journal of Sociology, 94, 95-120. 
de Soto, H. (2000). The mystery of capital: Why capitalism triumphs in the west and fails everywhere else. London, UK: Transworld Publishers.

Durlauf, S. N. (2002). Bowling alone: A review essay. Journal of Economic Behavior and Organization, 47(3), 259-273.

Dyer, W. G. (2006). Examining the "family effect" on firm performance. Family Business Review, 19(4), 253-273.

Enz, C. A., Dollinger, M. J., \& Daily, C. M. (1990). The value orientations of minority and non-minority small business owners. Entrepreneurship Theory and Practice, 15(1), 23-35.

Farlie, R., \& Robb, A. (2007). Why are Black-owned businesses less successful than White-owned businesses? The role of families, inheritances, and business human capital. Journal of Labor Economics, 25(2), 289-323.

Fulkerson, G., \& Thompson, G. (2008). The evolution of a contested concept: A metaanalysis of social capital definitions and trends (1988-2006). Sociological Inquiry, 78(4), 536-557.

Gersick, K., Davis, J., Hampton, M., \& Lansberg, I. (1997). Generation to generation: Life cycles of the family business. Boston MA: Harvard Business School Press.

Guiso, L., Sapienza, P., \& Zingales, L. (2004). The role of social capital in financial development. American Economic Review, 94(3), 526-556.

Habbershon, T. G., Williams, M., \& MacMillan, I. C. (2003). A unified systems perspective of family firm performance. Journal of Business Venturing, 18(4), 451-465.

Hanifan, L. J. (1916). The rural school community center. Annals of the American Academy of Political and Social Sciences, 67, 130-138.

Hirsch, J. (1989). 4 banks called biased on new accounts. New York Times, p. 3.

Harris, I. C. (2009). Ethnicity effects on the family business entrepreneurial process. Family Business Review, 22(3), 293-296.

Hoffman, J. H. (2006). Achieving sustained competitive advantage: A family capital theory. Family Business Review, 19(2), 135-145.

Karra, N., Tracey, P., \& Phillips, N. (2006). Altruism and agency in the family firm: Exploring the role of family, kinship, and ethnicity. Entrepreneurship, Theory, \& Practice, 30(6), 861-877.

Kim, J., \& Mahoney, J. (2010). A strategic theory of the firm as a nexus of incomplete contracts: A property rights approach. Journal of Management, 36(4), 806-826.

Khavul, S., Bruton, G., \& Wood, E. (2009). Informal family business in Africa. Entrepreneurship, Theory, \& Practice, 33(6), 1219-1238.

Kirzner, I. (1973). Competition and entrepreneurship. Chicago, IL: University of Chicago Press.

Lansberg, I. (1999). Succeeding generations: Realizing the dream of families in business. Boston, MA: Harvard Business School Press.

Lee, K. (1987). Making progress-but still a long way to go. Industrial Society, 18-20.

Libecap, G. (1989). Contracting for property rights. New York, NY: Cambridge University Press.

Masuo, D. M., \& Malroutu, Y. L. (2008). A profile of minority business owner (Entrepreneur's Toolbox ET-10). Retrieved from University of Hawaii, College of Tropical Agriculture and Human Resources Scholarspace 
website: http://scholarspace.manoa.hawaii.edu/bitstream/handle/10125/13443/ET10.pdf? sequence $=1$.

Molina-Morales, F. X., \& Martinez-Fernandez, M. T. (2009). Too much love in the neighborhood can hurt: How an excess of intensity and trust in relationships may produce negative effects on firms. Strategic Management Journal, 30(9), 10131023.

Nahapiet, J., \& Ghoshal, S. (1998). Social capital, intellectual capital, and the organizational advantage. Academy of Management Review, 23(2), 242-266.

Nwankwo, O. A., \& Osho, G. S. (2010). An empirical analysis of corporate survival and growth: Evidence from efficient working capital management. International Journal of Scholarly Academic Intellectual Diversity, 12(1), 1-13.

Pearson, A. W., Carr, J., \& Shaw, J. (2008). Toward a theory of familiness: A social capital perspective. Entrepreneurship, Theory, \& Practice, 32(6), 949-969.

Penrose, E. (2009). The theory of the growth of the firm. New York, NY: Oxford University Press.

Peredo, A. M., \& Chrisman, J. J. (2006). Toward a theory of community based enterprise. Academy of Management Review, 31(2), 309-328.

Portes, A. (1998). Social capital: Its origins and applications in modern sociology. Annual Review of Sociology, 24, 1-24.

Puryear, A., Rogoff, E., Lee, M., Heck, R. K., Grossman, E., Haynes, G., \& Onochie, J. (2008). Sampling minority business owners and their families: The understudies entrepreneurial experience. Journal of Small Business Management, 46(3), 422455.

Putnam, R. D. (2000). Bowling alone: The collapse and revival of American community. New York, NY: Simon \& Schuster.

Reimer, B., Lyons, T., Ferguson, N., \& Palanco, G. (2008). Social capital as social relations: The contribution of normative structures. The Sociological Review, 56(2), 256-274.

Reynolds, P. D., Carter, N. M., Gartner, W. B., \&. Greene, P. G. (2004). The prevalence of nascent entrepreneurs in the United States: Evidence from the panel study of entrepreneurial dynamics. Small Business Economics, 23(4), 263-284.

Robb, A. M., \& Fairlie, R. W. (2007). Access to financial capital among U.S. businesses: The case of African American firms. Annals of the American Academy of Political and Social Science, 613, 47-72.

Ruggles, S. (1994). The origins of African-American family structure. American Sociological Review, 59(1), 136-151.

Sherif, K., Hoffman, J., \& Thomas, B. (2006). Can technology build organizational social capital? The case of a global IT consulting firm. Information \& Management, 43(7), 795-804.

Singh, R., Knox E., \& Crump M. (2008). Opportunity recognition differences between Black and White nascent entrepreneurs: A test of Bhave's model. Journal of Developmental Entrepreneurship, 13(1), 59-75.

Smith, G. (2009). East Africa: Extended families with many rights. Entrepreneurship, Theory, \& Practice, 33(6), 1239-1244.

Steier, L. (2007). New venture creation and organization: A familial sub-narrative. Journal of Business Research, 60(10), 1099-1107. 
Sype, G. (2011). We have built it but they have not come: Preliminary assessment of a minor in entrepreneurship. Journal of Behavioral \& Applied Management, 12(3), 217-228.

Toossi, M. (2002, May). A century of change: The U.S. labor force, 1950-2050. Monthly Labor Review, 15-28.

Wiig, K. (2004). People-focused knowledge management: How effective decision making leads to corporate success. Oxford, UK: Elsevier ButterworthHeinemann. 